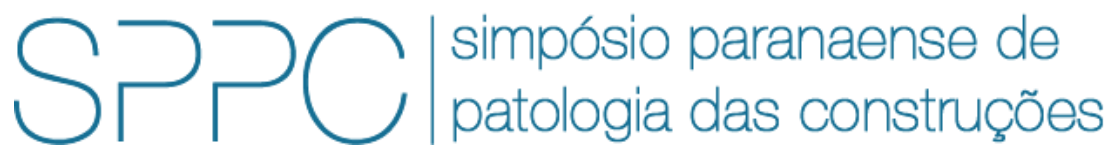

ISSN 2526-7248 artigo 2SPPC1011, pp. 117-128, 2017

\title{
Aplicação de solução comercial alcalina para realcalinização química de concretos carbonatados
}

\author{
Giovana Costa Réus ${ }^{1}$, Ariel Ribeiro de Jesus² e Marcelo Henrique Farias de Medeiros ${ }^{3}$ \\ ${ }^{1}$ Msc., UFPR, gio_reus@yahoo.com.br \\ 2 Graduanda, UFPR, ariel.arj95@hotmail.com \\ 3 Prof. Dr., UFPR, medeiros.ufpr@gmail.com
}

Resumo: A carbonatação é uma manifestação patológica que acomete estruturas de concreto armado, diminuindo sua vida útil. Essa manifestação patológica ocorre por meio da reação entre o dióxido de carbono presente na atmosfera com componentes da pasta hidratada de cimento, diminuindo $\mathrm{o} \mathrm{pH}$ do concreto e tornando as armaduras desprotegidas frente à corrosão. A realcalinização química é um método de tratamento para estruturas carbonatadas que visa elevar novamente $\mathrm{opH}$ do concreto. $\mathrm{O}$ presente trabalho tem por objetivo testar uma solução alcalina comercializada no mercado nacional, com a função de realcalinizar quimicamente estruturas de concreto. Para tanto foram utilizados quatro métodos de aplicação distintos: spray, trincha, manta e imersão. Observou-se que os métodos de spray e trincha não foram capazes de realcalinizar o concreto carbonatado. Os métodos manta e imersão apresentaram resultados promissores, com $10,87 \mathrm{~mm}$ e 15,62 mm de realcalinização ao final do tratamento. Conclui-se que a solução comercial não é capaz de realcalinizar concretos carbonatados quando aplicada por meio de spray e trincha como recomenda o fabricante. Conclui-se também que a solução em si é eficiente, sendo que, o problema de fato é o método de aplicação sugerido pelo fabricante. Isso é evidenciado, pois quando a solução comercial é aplicada por meio de imersão e manta, há realcalinização do concreto carbonatado.

Palavras-chave: Realcalinização, carbonatação, solução alcalina.

Abstract: Carbonation is a pathological manifestation that affects reinforced concrete structures, reducing its useful life. This pathological manifestation occurs through the reaction between the carbon dioxide present in the atmosphere with components of the hydrated mass of cement, decreasing the $\mathrm{pH}$ of the concrete and becoming as unprotected against corrosion. Chemical realkalisation is a treatment method for the carbonate structures that raise the $\mathrm{pH}$ of the concrete. The present work has the objective of testing an alkaline solution commercialized in the national market, with a function of chemically realcalinisation concrete structures. Four different application methods were used: spray, brush, blanket and immersion. It was observed that the spraying and brushing methods were not obtained from realkaline the carbonated concrete. The manual methods and the results presented with $10.87 \mathrm{~mm}$ and $15.52 \mathrm{~mm}$ of realcalinization at the end of the treatment. It is concluded that a commercial solution is not able to concrete concrete carbonates when applied by means of spray and brush as recommended by the manufacturer. It is also concluded that a solution in itself is efficient, and, in fact, the problem is the method of application suggested by the manufacturer. This is evidenced, when a commercial solution is applied by immersion and blanket, there is realcalinization of the carbonated concrete.

Keywords: Realkalisation, carbonation, alkaline solution. 
RÉUS, G. C.; JESUS, A. R.; MEDEIROS, M. H. F. APLICAÇÃO DE SOLUÇÃO COMERCIAL ALCALINA PARA REALCALINIZAÇÃO QUÍMICA DE CONCRETOS CARBONATADOS. $2^{\circ}$ Simpósio Paranaense de Patologia das Construções (2० SPPC), artigo2SPPC1011, pp. 117-128, 2017. DOI: 10.4322/2SPPC.2017.011

\section{Introdução}

As estruturas de concreto armado estão sujeitas à interação com o ambiente a qual estão inseridas. Quanto mais agressivo o ambiente, mas manifestações patológicas tendem a surgir na estrutura. A aplicação de métodos para recuperação de estruturas tem por objetivo aumentar a vida útil das mesmas, postergando a geração resíduos de demolição e desmobilização de material para novas construções.

A realcalinização química é um método de tratamento para estruturas carbonatadas que visa elevar novamente o $\mathrm{pH}$ do concreto, aumentando a vida útil das estruturas. Há atualmente no mercado brasileiro um produto sendo vendido com esta finalidade. O presente trabalho tem por objetivo testar esse produto por meio de métodos de aplicação indicados pelo fabricante (métodos do spray e trincha). Testaram-se também outros dois métodos de aplicação, o método da manta e o método de imersão.

\section{Revisão Bibliográfica}

O concreto é um material que possui elevada alcalinidade em função dos elementos solubilizados em sua rede de poros [1]. Esta elevada alcalinidade confere proteção às armaduras frente à corrosão [2]. Isso ocorre em função da película de passivação que se forma em torno das armaduras. Essa película é um filme fino de óxido de ferro extremamente aderente ao aço.

A carbonatação é o processo físico-químico, onde o dióxido de carbono $\left(\mathrm{CO}_{2}\right)$ presente na atmosfera reage com íons alcalinos presente no interior do concreto. Primeiramente $\mathrm{O} \mathrm{CO}_{2}$ reage com a água, formando o ácido carbônico $\left(\mathrm{H}_{2} \mathrm{CO}_{3}\right)$. $\mathrm{O}$ ácido carbônico reage então com o íons de hidróxido de cálcio $(\mathrm{Ca}(\mathrm{OH}) 2)$, hidróxido de sódio $(\mathrm{NaOH})$ e hidróxido de potássio $(\mathrm{KOH})$. O final da reação resulta na formação de carbonato de cálcio $\left(\mathrm{CaCO}_{3}\right)$ [3]. $\mathrm{O}$ carbonato de cálcio possui o $\mathrm{pH}$ menor que os hidróxidos que o deram origem, por isso há a diminuição da alcalinidade do concreto.

As reações de carbonatação dependem da difusão do $\mathrm{CO}_{2}$ no interior do concreto, portanto ocorrem da face externa para a face interna da estrutura. A linha que separa a região de alta e de baixa alcalinidade é denominada frente de carbonatação [3-4], como é possível observar na Figura 1. 
RÉUS, G. C.; JESUS, A. R.; MEDEIROS, M. H. F. APLICAÇÃO DE SOLUÇÃO COMERCIAL ALCALINA PARA REALCALINIZAÇÃO QUÍMICA DE CONCRETOS CARBONATADOS. $2^{\circ}$ Simpósio Paranaense de Patologia das Construções (2० SPPC), artigo2SPPC1011, pp. 117-128, 2017. DOI: 10.4322/2SPPC.2017.011

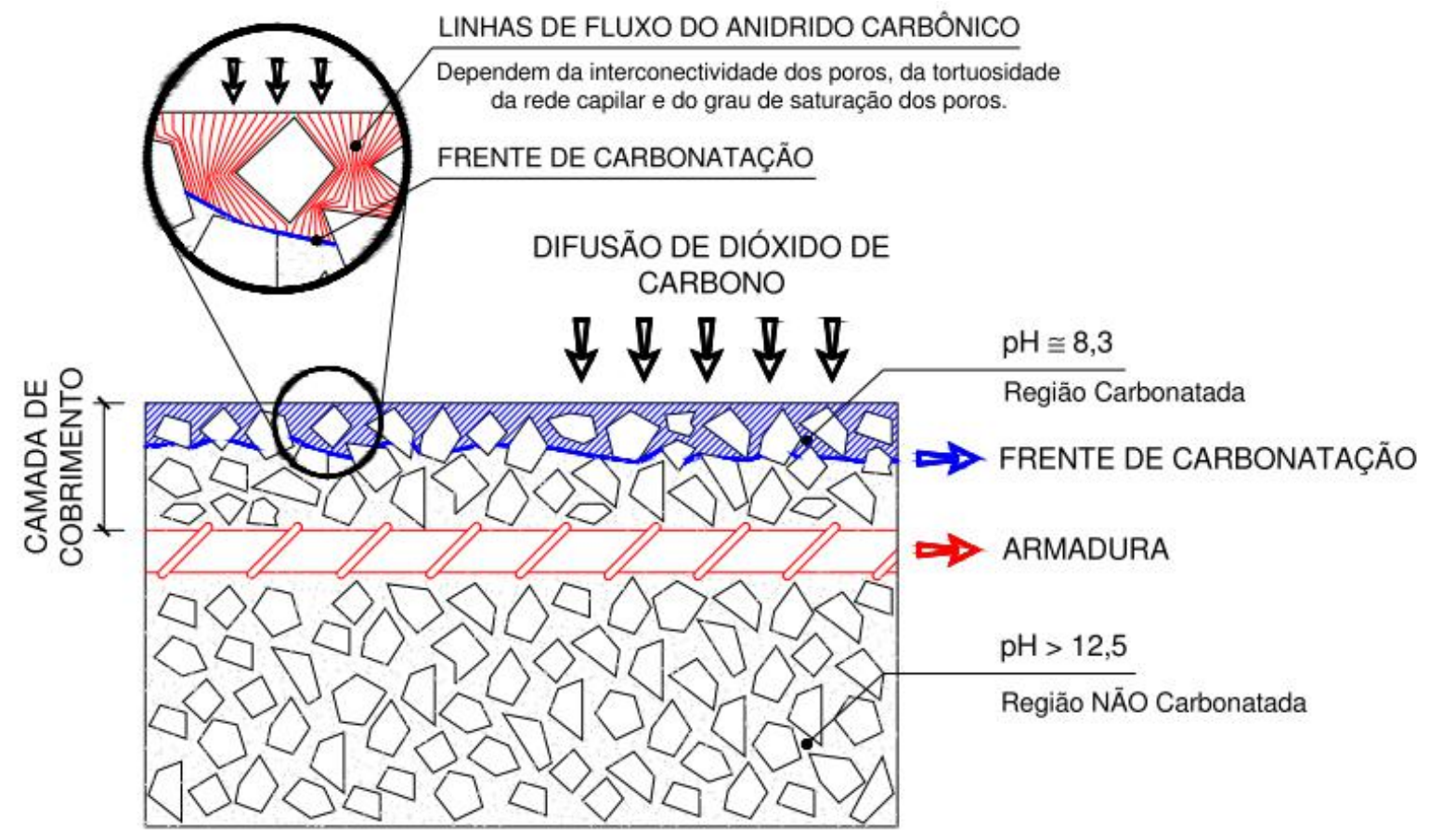

Figura 1: Representação esquemática do mecanismo de carbonatação.[3]

Após a frente de carbonatação atingir as armaduras a película de passivação é quebrada e as armaduras ficam contidas em um ambiente propício para 0 surgimento da corrosão. A corrosão de armaduras contidas em um concreto carbonatado pode ocorrer como se estivesse exposta à atmosfera [5].

A realcalinização é uma técnica de tratamento para concretos carbonatados, e seu objetivo é elevar o $\mathrm{pH}$ do concreto, a fim de reestabelecer sua alcalinidade. A realcalinização pode ser realizada por técnicas eletroquímicas ou químicas. A realcalinização química baseia-se na absorção e difusão de soluções alcalinas para o interior do concreto. Os íons alcalinos reagem com a fase líquida dos poros do concreto, resultando em novos produtos com o pH mais elevado [6]. A Figura 2 mostra o processo da realcalinização química em condições de laboratório. A elevação do $\mathrm{pH}$ do concreto ocorre de fora para dentro do concreto, como é possível observar na Figura 3. 
RÉUS, G. C.; JESUS, A. R.; MEDEIROS, M. H. F. APLICAÇÃO DE SOLUÇÃO COMERCIAL ALCALINA PARA REALCALINIZAÇÃO QUÍMICA DE CONCRETOS CARBONATADOS. $2^{\circ}$ Simpósio Paranaense de Patologia das Construções (2० SPPC), artigo2SPPC1011, pp. 117-128, 2017. DOI: 10.4322/2SPPC.2017.011

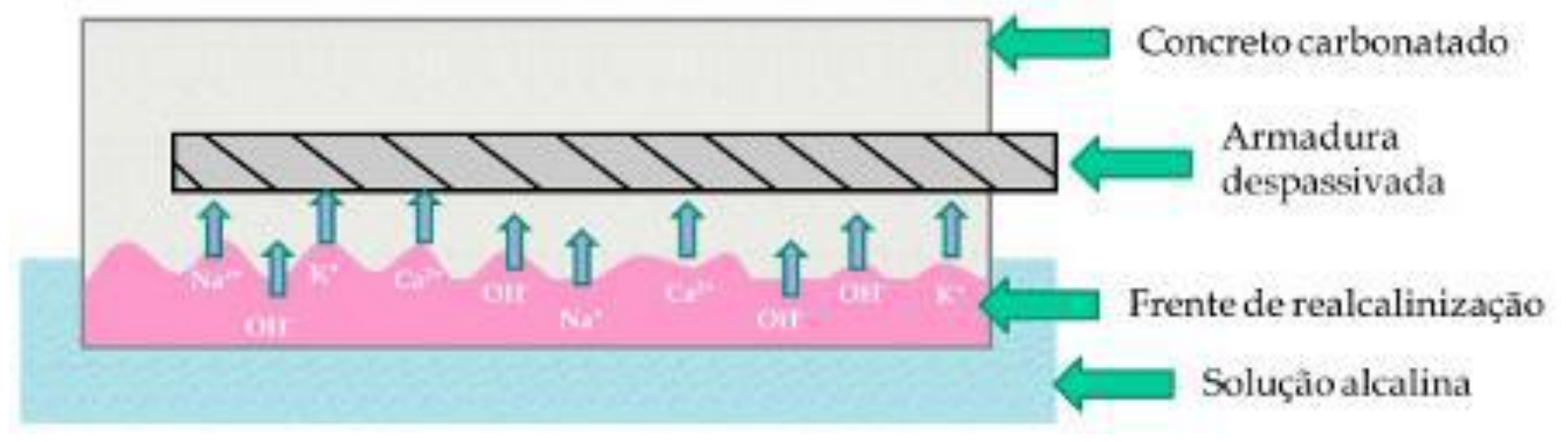

Figura 2: Esquema de realcalinização química [6].

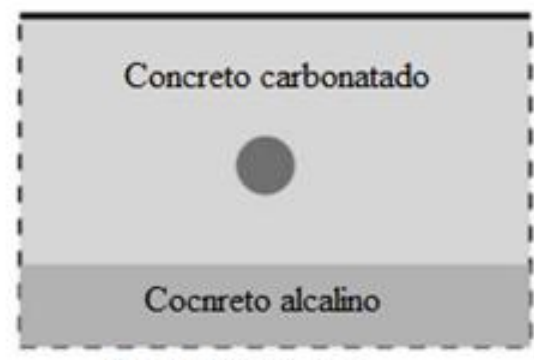

Antes do tratamento

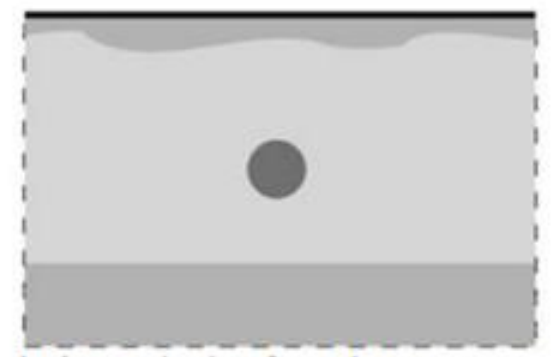

Após as primeiras fases do tratamento

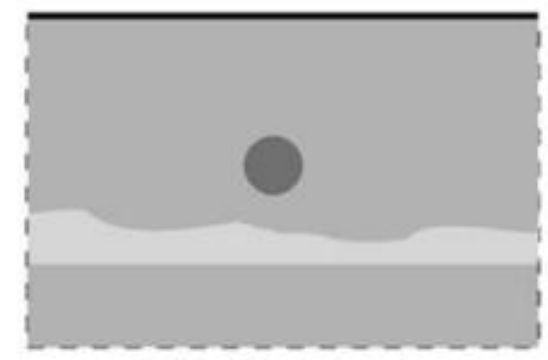

Ao final do tratamento

Figura 3: Evolução da realcalinização química ao longo do tempo [7].

\section{Metodologia}

\subsection{Materiais e preparo das amostras}

Os materiais empregados foram cimento Portland, agregado miúdo e agregado graúdo. O cimento utilizado foi do tipo CP-V ARI já que sua composição é livre de adições minerais. Essas adições podem influenciar o avanço da carbonatação no interior do concreto, o que poderia prejudicar os resultados desse estudo. A massa específica do cimento utilizado é de $3,09 \mathrm{~g} / \mathrm{m}^{3}$ (ensaio realizado de acordo com a NBR NM 23 [8]).

O agregado miúdo é uma areia quartzosa com fonte em São Luis do Puruña, no estado do Paraná. Seu módulo de finura é 1,76, com diâmetro máximo de 1,18 mm e massa específica e unitária $3,44 \mathrm{~g} / \mathrm{cm}^{2}$ e $1,70 \mathrm{~g} / \mathrm{cm}^{2}$, respectivamente, dessa forma é classificada como areia fina.

O agregado graúdo tem origem basáltica e provém da cidade de São Mateus do Sul, no estado do Paraná. E classificado como agregado lamelar por ter índice de forma 2,56 e possui massa específica de $2,75 \mathrm{~g} / \mathrm{cm}^{2}$ e massa unitária de $1,63 \mathrm{~g} / \mathrm{cm}^{2}$, seu diâmetro máximo é de $25 \mathrm{~mm}$.

Os corpos de prova foram moldados com traço 1:2,60:3,20, com relação água/cimento de 0,70. Apesar da NBR 6118 [9] especificar valores menores de relação água/cimento, a escolha se deu pelo fato das estruturas tratadas serem 
RÉUS, G. C.; JESUS, A. R.; MEDEIROS, M. H. F. APLICAÇÃO DE SOLUÇÃO COMERCIAL ALCALINA PARA REALCALINIZAÇÃO QUÍMICA DE CONCRETOS CARBONATADOS. $2^{\circ}$ Simpósio Paranaense de Patologia das Construções (2० SPPC), artigo2SPPC1011, pp. 117-128, 2017. DOI: 10.4322/2SPPC.2017.011

antigas e terem seus critérios baseados em normas da época em que foram construídas.

A cura das amostras adotada foi por imersão durante 28 dias e o sazonamento em camâra seca com temperatura e umidade controlados $\left(23^{\circ} \mathrm{C}\right.$ e $60 \%$ de umidade), durante 28 dias. Baseou-se no trabalho de Possan [10] para a definição da cura e sazonamento adotados. As amostras passaram por ensaio de carbonatação acelerada até que a espessura carbonatada fosse de $25 \mathrm{~mm}$, pois essa é a profundidade prevista pela NBR 6118 [9] para lajes de concreto armado em ambiente urbano.

A solução alcalina aplicada é um produto comercial disponível no Brasil para realcalização de estruturas de concreto armado carbonatadas. A sua concentração e composição não são informadas pelo fabricante.

\subsection{Ensaios realizados}

A carbonatação acelerada foi realizada em camâra de carbonatação com valores constantes de umidade, temperatura e concentração de $\mathrm{CO}_{2}$, sendo eles, $60 \pm 5 \%$, $40 \pm 1^{\circ} \mathrm{C}$ e $5 \pm 1 \%$ respectivamente. As medidas das profundidades de realcalização e carbonatação foram feitas utilizando solução alcoólica de fenolftaleína. Quando esse indicador químico é aplicado na superfície do material e o pH for superior a 8,3, o material apresentará cor vermelho carmim. Essa solução foi produzida com $10 \mathrm{~g}$ de fenolftaleína misturadas em $700 \mathrm{ml}$ de etanol puro. Depois foram adicionados 300 $\mathrm{ml}$ de água destilada de acordo com o proposto pela RILEM 1988 CPC-18 [11].

Os corpos de prova considerados foram rompidos, limpos com pincel e a solução foi aspergida na superfície recém-fraturada da amostra. Realizaram-se nove leituras da profundidade de carbonatação no corpo de prova com a utilização de um paquímetro, a divisão da amostra em nove partes foi feita visualmente conforme apresentado na

Figura 4.

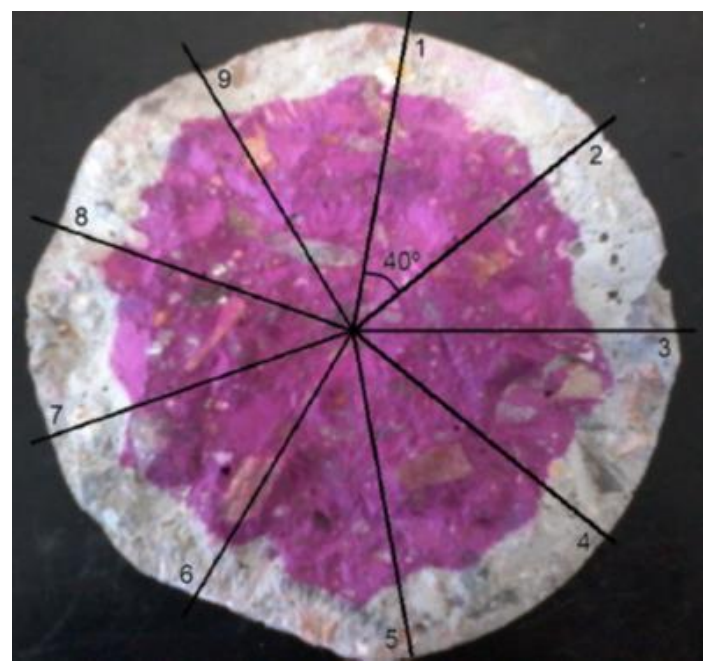

Figura 4: Medição da carbonatação e realcalinização [14]. 
RÉUS, G. C.; JESUS, A. R.; MEDEIROS, M. H. F. APLICAÇÃO DE SOLUÇÃO COMERCIAL ALCALINA PARA REALCALINIZAÇÃO QUÍMICA DE CONCRETOS CARBONATADOS. $2^{\circ}$ Simpósio Paranaense de Patologia das Construções (2० SPPC), artigo2SPPC1011, pp. 117-128, 2017. DOI: 10.4322/2SPPC.2017.011

Foram realizados ensaios de resistência à compressão [12] e absorção de agua por sucção capilar [13], para verificar possíveis mudanças nessas propriedades do concreto. Essas propriedades foram analisadas visto que a resistência à compressão do concreto é umas das principais propriedades desse material, e não deve sofrer mudanças significativas após passar por tratamentos que visam melhorar sua durabilidade, com é o caso da realcalinização. Foram utilizadas 3 amostras para cada tipo de método de aplicação em cada ensaio. Antes da realização destes ensaios, as amostras foram secas até constância de massa.

Os quatro métodos utilizados (Figura 5) para a aplicação da realcalinização foram os métodos de imersão, manta, spray e trincha. O método de imersão é realizado através da imersão completa do corpo de prova na solução alcalina. O método da manta consiste em envolver a amostra em uma manta umedecida com solução alcalina. A manta é composta por polietileno tereftalato (PET) reciclado, esse material foi utilizado para evitar que ela se deteriorasse devido ao caráter corrosivo da solução por ser básica. Além da manta, o corpo de prova também foi envolvido com um filme plástico para evitar a evaporação do produto. Ambos os métodos (imersão e manta) foram aplicados durantes 14 dias.

As instruções de aplicação da solução alcalina fornecidas pelo fabricante foram utilizadas nos métodos de spray e trincha. Certificou-se que a superfície da amostra se encontrava limpa e seca para então aplicar 5 camadas do produto com intervalo de 30 minutos entre camadas.

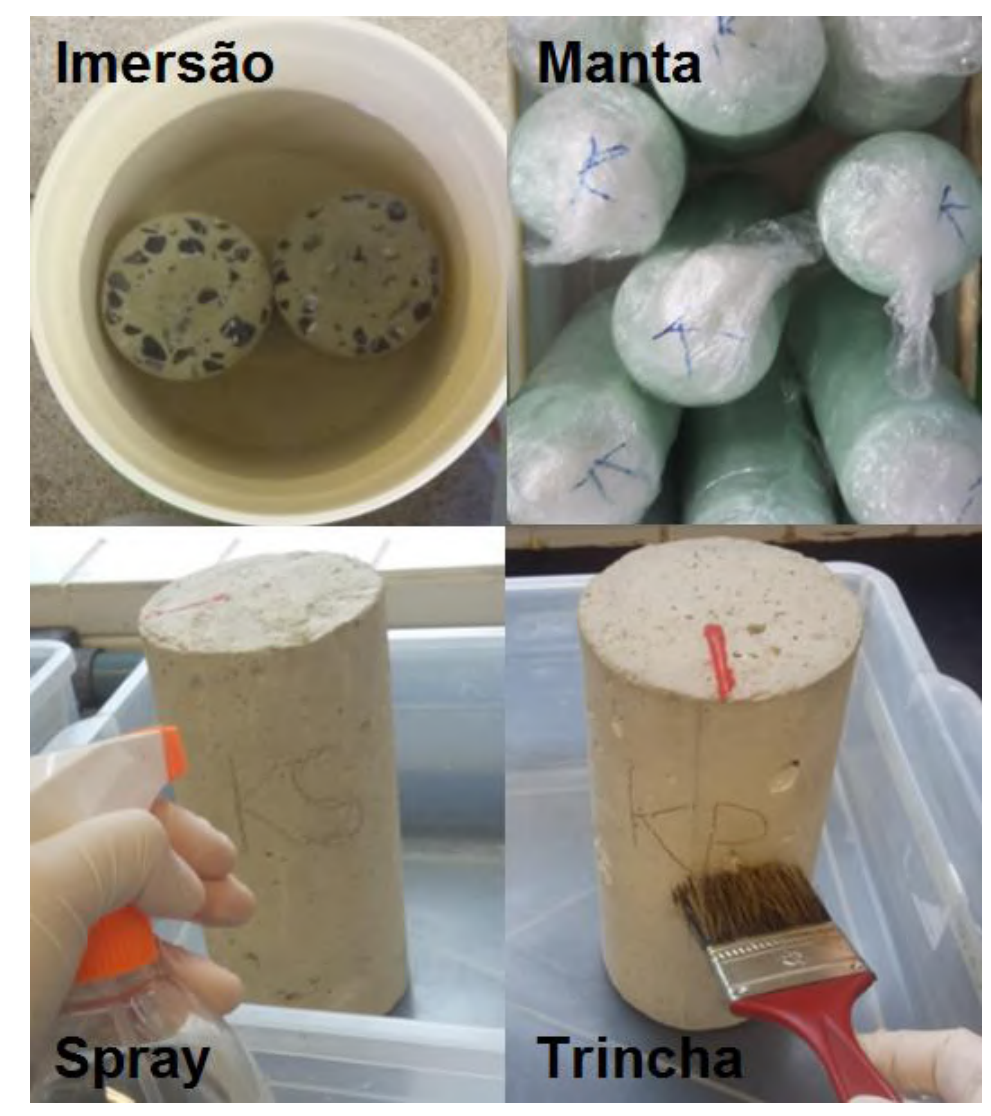

Figura 5: Método de aplicação por imersão, manta, spray e trincha. 


\section{Resultados}

A carbonatação se da forma mais acelerada nas primeiras idades do concreto, ou seja, possui um comportamento exponencial [5]. A equação clássica utilizada para cálculo da profundidade de carbonatação é mostrado na Equação 1, onde $e_{c}$ é a espessura carbonatada em $\mathrm{mm}, t$ é o tempo em semanas e $k_{c o 2}$ é o coeficiente de carbonatação.

$$
e_{c}=k_{c o 2} \cdot \sqrt{t}
$$

As amostras foram submetidas à camâra de carbonatação durante 53 semanas, a profundidade encontrada após esse período foi em média de 31,64 mm. A Figura 6 mostra a variação da profundidade de carbonatação ao longo do tempo. $O$ coeficiente de carbonatação encontrado é 3,47.

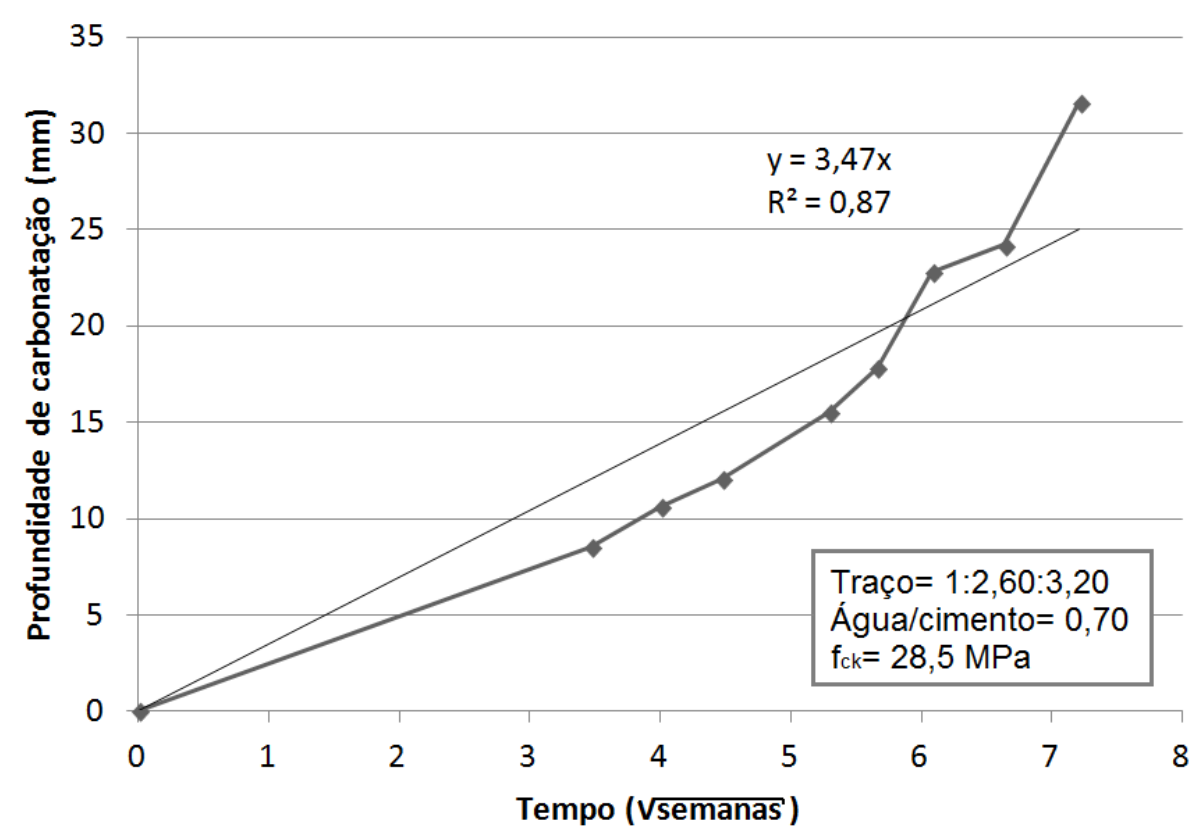

Figura 6: Profundidade de carbonatação das amostras ao longo do tempo.

A profundidade de realcalinização encontrada após o tratamento com solução comercial pelos métodos de imersão, manta, spray e trincha, estão expostas na Figura 7. 
RÉUS, G. C.; JESUS, A. R.; MEDEIROS, M. H. F. APLICAÇÃO DE SOLUÇÃO COMERCIAL ALCALINA PARA REALCALINIZAÇÃO QUÍMICA DE CONCRETOS CARBONATADOS. $2^{\circ}$ Simpósio Paranaense de Patologia das Construções (2० SPPC), artigo2SPPC1011, pp. 117-128, 2017. DOI: 10.4322/2SPPC.2017.011

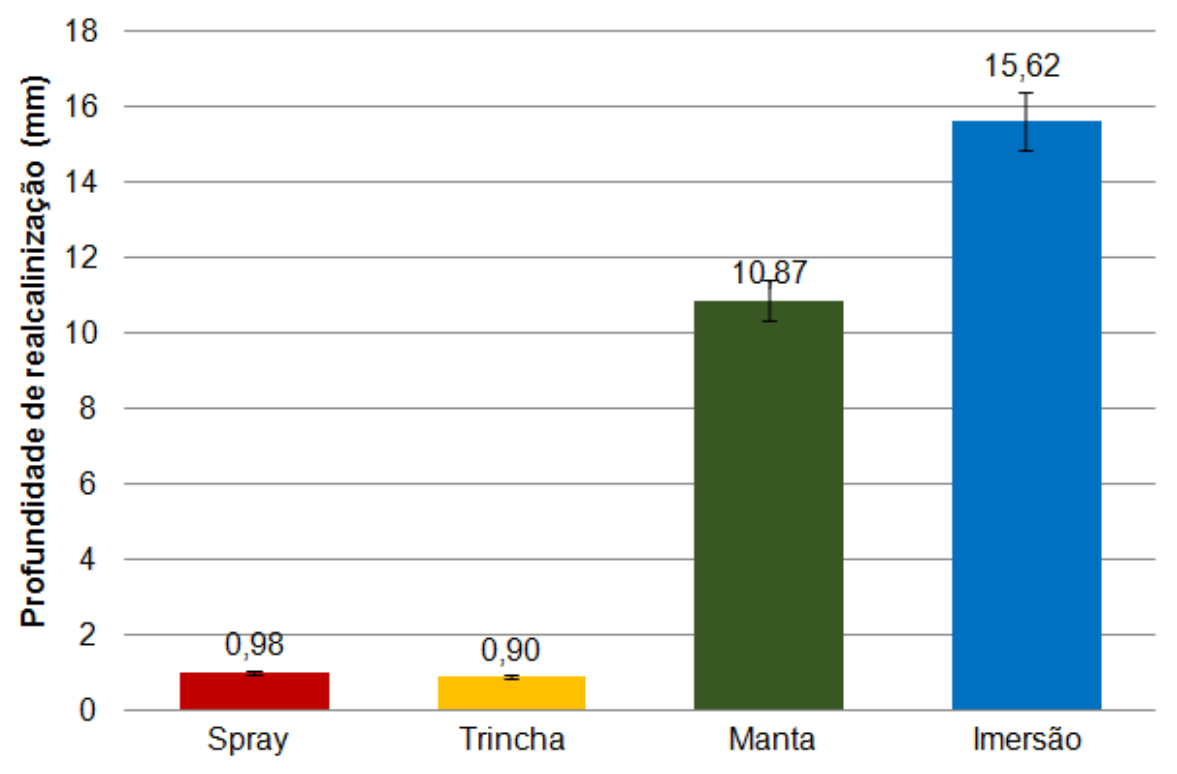

Figura 7: Profundidade de realcalinização das amostras.

É possível observar que os métodos propostos pelo fabricante na aplicação da solução comercial (trincha e spray) foram pouco eficientes, pois apresentaram baixas profundidades de realcalinização $(0,98 \mathrm{~mm}$ e $0,90 \mathrm{~mm}$, respectivamente). Nas aplicações contínuas, manta e imersão, houve maior profundidade de realcalinização $(10,87 \mathrm{~mm}$ e $15,62 \mathrm{~mm}$, respectivamente). Os valores de profundidade de realcalinização obtidos com os métodos de trincha e spray correspondem a $9,1 \%$ e $11,3 \%$ do valor obtido com o método de imersão. A Figura 8 apresenta as amostras após a realcalinização com os métodos de aplicação por spray, trincha, manta e imersão. O método da trincha também foi testados por RÉUS et. al., 2015a e RÉUS et. al., 2015b [7][14], onde também não foram obtidos resultados satisfatórios por meio deste método de aplicação.

A Figura 9 e a Figura 10 apresentam resultados para os ensaios de resistência a compressão e absorção de água por sucção capilar, respectivamente. Observa-se que a amostra não carbonatada foi ensaiada com a mesma idade das amostras realcalinizadas. Obtiveram-se diferenças consideráveis entre as amostras carbonatadas e não carbonatadas para ambos ensaios, o que corrobora com os dados encontrados por Medeiros e Helene [15]. É possível que a colmatação dos poros em consequência das reações internas do concreto, resultando na transformação da portlandita em carbonato de cálcio, seja a principal causa dessas divergências. 
RÉUS, G. C.; JESUS, A. R.; MEDEIROS, M. H. F. APLICAÇÃO DE SOLUÇÃO COMERCIAL ALCALINA PARA REALCALINIZAÇÃO QUÍMICA DE CONCRETOS CARBONATADOS. $2^{\circ}$ Simpósio Paranaense de Patologia das Construções (20 SPPC), artigo2SPPC1011, pp. 117-128, 2017. DOI: 10.4322/2SPPC.2017.011

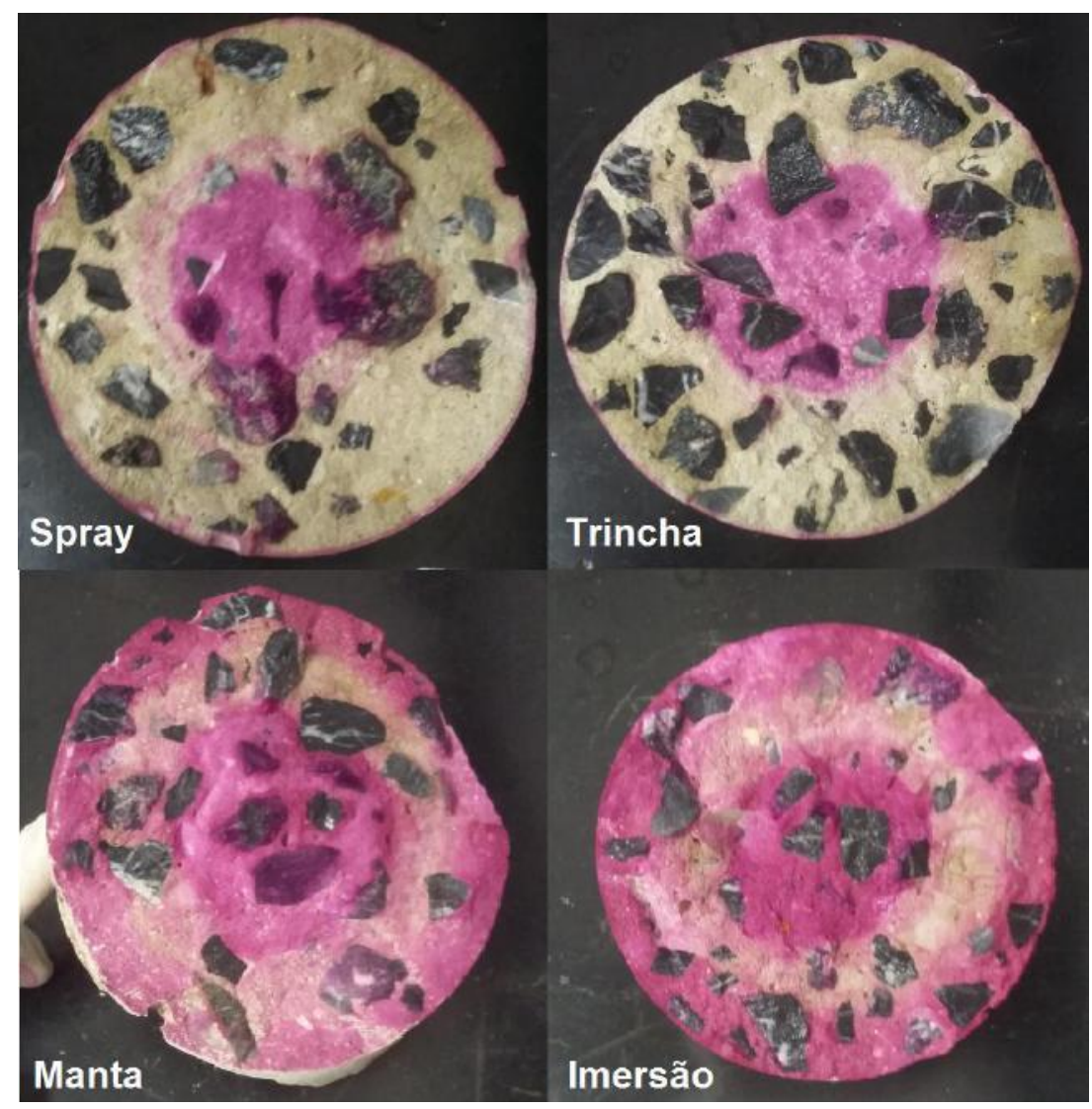

Figura 8: Final do tratamento de realcalinização com solução comercial e métodos de spra, trincha, manta e imersão.

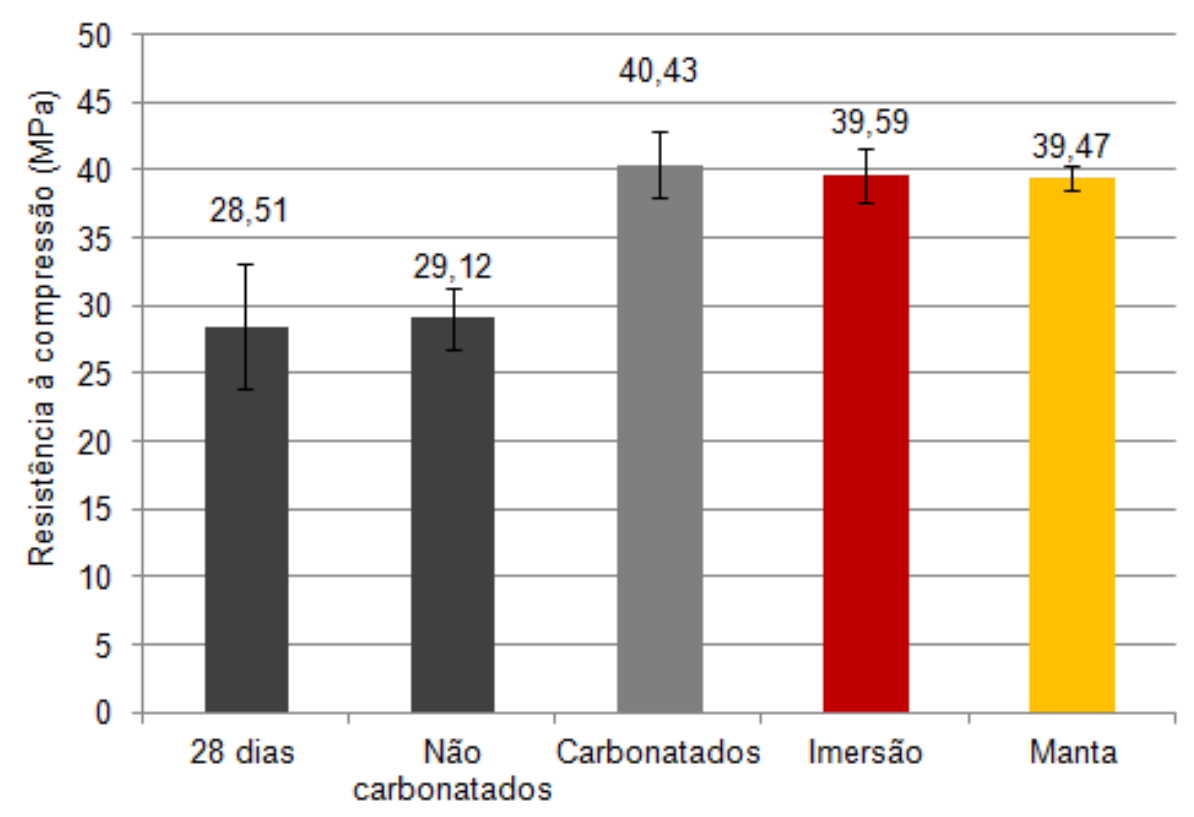

Figura 9: Resistência à compressão das amostras.

Fonte: (Os autores) 
RÉUS, G. C.; JESUS, A. R.; MEDEIROS, M. H. F. APLICAÇÃO DE SOLUÇÃO COMERCIAL ALCALINA PARA REALCALINIZAÇÃO QUÍMICA DE CONCRETOS CARBONATADOS. $2^{\circ}$ Simpósio Paranaense de Patologia das Construções (2० SPPC), artigo2SPPC1011, pp. 117-128, 2017. DOI: 10.4322/2SPPC.2017.011

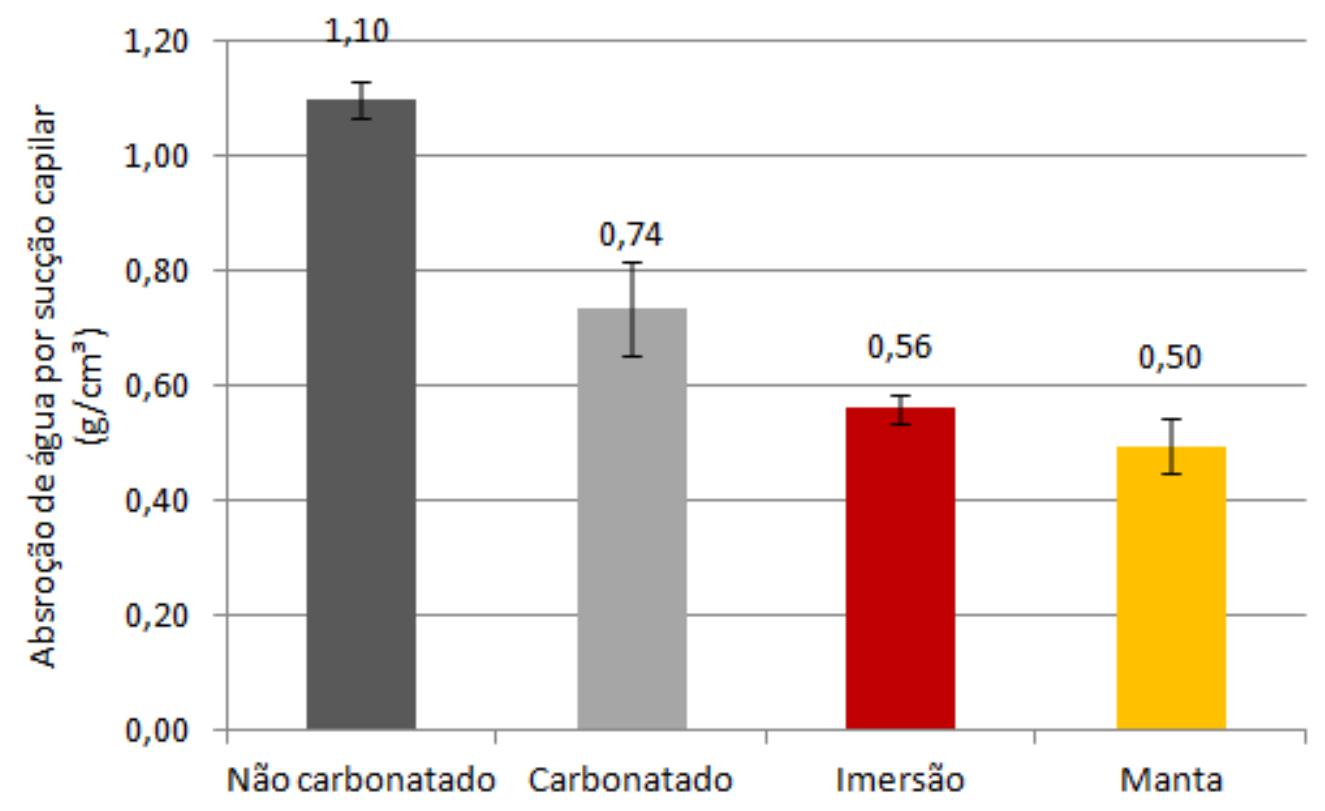

Figura 10 - Absorção de água por sucção capilar das amostras.

Fonte: (Os autores)

Através do teste de Tukey com 95\% de confiança, que a resistência à compressão anterior a realcalinização não apresentou alterações significativas em relação à obtida posteriormente. Esse resultado está de acordo com os estudos de Araujo [16]. Nos ensaios para verificar a absorção de água por capilaridade houve alterações significativas nos resultados entre antes e depois do procedimento de realcalinização. O fato de não haver alterações significativas tanto na resistência à compressão quanto na absorção por sucção capilar do concreto leva a crer que não houveram mudanças relevantes na microestrutura do concreto tratado.

\section{Conclusões}

- Os métodos propostos pelo fabricante da solução comercial (spray e trincha) não apresentaram profundidades realcalinizadas que garantam a recuperação da estrutura de concreto carbonatadas;

- A solução comercial é capaz de realcalinizar concretos carbonatados quando aplicada por meio dos métodos de manta e imersão;

- A solução comercial tem potencial para obtenção de resultados satisfatórios de realcalinização, desde o que método de aplicação sugerido pelo fabricante seja modificado.

\section{Agradecimentos}

Este trabalho foi desenvolvido no Departamento de Construção Civil e no Programa de Pós-graduação em Engenharia de Construção Civil da Universidade do Paraná. Agradecemos ao Conselho Nacional de Desenvolvimento Científico e Tecnológico (CNPq) pelos equipamentos adquiridos que viabilizaram a realização do presente trabalho. 
RÉUS, G. C.; JESUS, A. R.; MEDEIROS, M. H. F. APLICAÇÃO DE SOLUÇÃO COMERCIAL ALCALINA PARA REALCALINIZAÇÃO QUÍMICA DE CONCRETOS CARBONATADOS. $2^{\circ}$ Simpósio Paranaense de Patologia das Construçōes ( $2^{\circ} \mathrm{SPPC}$ ), artigo2SPPC1011, pp. 117-128, 2017. DOI: 10.4322/2SPPC.2017.011

\section{Referências}

[1] BLANCO, G.; BAUTISTA, A.; TAKENOUTI, H. EIS study of passivation of austenitic and duplex stainless steels reinforcements in simulated pore solutions. Cement and Concrete Research, v. 28, p. 212-219, 2006.

[2] GOÑI, S.; ANDRADE, C. Synthetic concrete pore solution chemistry and rebar. Cement and Concrete Research, v. 20, n. c, p. 525-539, 1990.

[3] HOPPE FILHO, J. Sistemas cimento, cinza volante e cal hidratada: mecanismo de hidratação, microestrutura e carbonatação de concreto. 247 p. Tese (Tese) — Universidade de São Paulo, 2008.

[4] HELENE, P. R. L. Contribuição ao estudo da corrosão em armaduras de concreto armado. 248 p. Tese (Tese) — Universidade de São Paulo, 1993.

[5] NEVILLE, A. M. Propriedades do concreto. 2. ed. São Paulo, 1997. ISBN 8572660682.

[6] ARAUJO, F. W. C. Estudo da repassivação da armadura em concretos carbonatados através da técnica de realcalinização química. Tese de doutorado - Universidade de São Paulo, 2009.

[7] RÉUS, G. C.; BECKER, A. C. C.; RAISDORFER, J. W.; SOUZA, D. J.; CEZARIO, H. C.; LENCZUK, B. S. T.; NIKKEL, S.; RODRIGUES, D. S.; MEDEIROS, M. H. F. Aplicação de soluções alcalinas para realcalinização de concretos carbonatados: uma alternativa para pontes de concreto armado In: 18ํㅡㄹ Encontro Nacional de Conservação Rodoviária, 2015, Foz do Iguaçu. 18o Encontro Nacional de Conservação Rodoviária. , 2015. v.1. p.1 15.

[8] ASSOCIAÇÃO BRASILEIRA DE NORMAS TÉCNICAS. NBR NM 23: Cimento portland e outros materiais em pó - determinação da massa. Rio de Janeiro, 2001.

[9] ASSOCIAÇÃO BRASILEIRA DE NORMAS TÉCNICAS. NBR 6118: Projeto de estruturas de concreto - procedimento. Rio de Janeiro, 2014.

[10] POSSAN, E. Carbonatação acelerada: estado da arte das pesquisas no Brasil. Ambiente Construído, p. 7-20, 2007.

[11] CASTRO, A. Influência das adições Minerais na Durabilidade do Concreto Sujeito à Carbonatação. Dissertação (Mestrado), 2003.

[12] ASSOCIAÇÃO BRASILEIRA DE NORMAS TÉCNICAS. NBR 5739: Concreto ensaio de compressão de corpos-de-prova cilíndrico. 2007.

[13] ASSOCIAÇÃO BRASILEIRA DE NORMAS TÉCNICAS. NBR 9779: Argamassa e concreto endurecidos - determinação da absorção de água por capilaridade. Rio de Janeiro, 2012. 
RÉUS, G. C.; JESUS, A. R.; MEDEIROS, M. H. F. APLICAÇÃO DE SOLUÇÃO COMERCIAL ALCALINA PARA REALCALINIZAÇÃO QUÍMICA DE CONCRETOS CARBONATADOS. $2^{\circ}$ Simpósio Paranaense de Patologia das Construções (2० SPPC), artigo2SPPC1011, pp. 117-128, 2017. DOI: 10.4322/2SPPC.2017.011

[14] RÉUS, G. C.; SOUZA, D. J.; BECKER, A. C. C.; RAISDORFER, J. W.; MEDEIROS, M. H. F. ANAIS DO 57ํ CONGRESSO BRASILEIRO DO CONCRETO CBC2015 - 57CBC 1 Aplicação de soluções alcalinas para realcalinização de concretos carbonatados In: 57ํㅡㄹ Congresso Brasileiro do Concreto, 2015, Bonito. 57 ${ }^{\circ}$ Congresso Brasileiro do Concreto. , 2015. v.1. p.115

[15] MEDEIROS, M. H. F.; HELENE, P. Estudo da carbonatação em concretos e argamassas. Revista engenharia. Ciência Tecnologia, v. 4, n. 4, p. 3-12, 2001.

[16] ARAUJO, F. W. C. Contribuição à viabilização da técnica de realcalinização do concreto carbonatado através da absorção/difusão de soluções alcalinas. Dissertação (Mestrado), 2004. 